\title{
Fractional order adaptive MRAC controller for an active suspension system
}

\author{
SEIF EDDINE KHELAS ${ }^{(1)^{*}}$, SAMIR LADACI ${ }^{(1)}$, YASSINE BENSAFIA $^{(2)}$ \\ (1) Department of E.E.A.National Polytechnic School of Constantine, Constantine Algeria \\ (2) Department of Electrical EngineeringUniversity of Bouira, Bouira, Algeria \\ *seifkhelas@gmail.com; samir Imadaci@yahoo.fr; bensafiay@yahoo.fr
}

\begin{abstract}
This paper investigates the use of fractional order operators in conventional model reference adaptive control (MRAC). A fractional adaptive controller is designed based on the use of a fractional-order parameter adjustment rule. Applied in numerical simulations for an active suspension system and compared with the conventional MRAC, it is shown that the performances of FOMRAC are superior to classical control schemes.
\end{abstract}

Keywords: fractional operator, fractional order system, Model Reference Adaptive Control, active suspension system.

\section{INTRODUCTION}

A considerable research effort is dedicated to the area of fractional order systems and their application in control engineering [1-3], and since few years many investigations have focused on the introduction of fractional order operators in adaptive control, and especially on Model Reference Adaptive Control (FOMRAC) [4-5]. In this approach adaptive algorithms allow the control of systems on which little information is known. The use of fractional model reference in the adaptive scheme has shown an improvement in system dynamics, due to the best model reference dynamical properties [6]. Besides, the introduction of fractional integration has proven the ability of fractional algorithms to guarantee stability with a highest level of performance then the integer order algorithms (it depends on the choice of the Integration fractional order) [7].

Many applications of FOMRAC have been presented in literature with encouraging results and advantageous performance [8]. This control scheme was to a robot arm position control in [5], and more recently to an industrial SCARA robot [9]. Another application to a hydraulic driven flight motion simulator is due to $\mathrm{Ma}$ et al [10], while $\mathrm{He}$ and Gong used this approach to control the temperature of a boiler burning system in [11]. A fractional adaptive control scheme for controlling the lateral position of an autonomous guided vehicle (AGV) is presented in [12]. The FOMRAC scheme is applied to conical tank level Supervision in [13] and a fractional-order insuline-glucose dynamic model control [14].

Recently, this fractional adaptive control approach was applied to a multisource renewable energy system [15] and the cruise control system for an Electric Vehicle [16]...etc.

Every vehicle moving on the randomly profiled road is exposed to vibrations which are harmful both for the passengers in terms of comfort and for the durability of the vehicle itself. Therefore the main task of a vehicle suspension is to ensure ride comfort and road holding for a variety of road conditions and vehicle maneuvers. There were many articles and papers which discussed this issue: $M$. Leegwater investigated an active suspension which is capable of leveling the car during cornering theoretically without consuming energy. As extreme cornering may be required to remain on the road or to avoid an obstacle, implementing the active suspension system improves safety [17]. Recently, Rezanoori et al. proposed a new method to improve passenger vehicle safety using intelligent functions in active suspension [18]. Rao [19] proposed the modeling and Control of Semi Active Suspension System for automobiles under MATLAB Simulink using PID controller whereas Talib and Darus [20] designed a self-tuning PID controller for its supervision. 
Ghasemalizadeh et al. [21] proposed a modified $\mathrm{H}_{\infty}$ control approach to improve the suspension system behavior.

This paper is structured as follows: Section II introduces the fractional order systems, with both integration and derivation definitions. Section III then introduces the model reference adaptive control (MRAC) problem and the use of fractional operators in the adaptation algorithm. The active suspension system modelization is presented in Section IV and simulation results of FOMRAC application are given in Section V. Finally some concluding remarks are presented in Section VI

\section{FRACTIONAL ORDER SYSTEMS}

The analysis in Bode plot of many natural processes, like transmission lines, dielectric polarization impedance, interfaces, cardiac rhythm, spectral density of physical wave, some types of noise [1], has allowed to observe a fractional slope. This type of process is known as $1 / f$ process or fractional order system. The used description equation into frequency domain of these processes is given as follows:

$$
X(s)=\frac{k}{\left(1+\frac{s}{p t}\right)^{m}}
$$

with $m$ : fractional exponent, pt : fractional pole which is the cut frequency and s : Laplace operator.

A. Definition of fractional integration

$$
\begin{aligned}
I_{c}^{\alpha} f(t) & \triangleq \int_{c}^{t} \frac{(t-\tau)^{\alpha-1}}{\gamma(\alpha)} f(\tau) d \tau \\
I_{c}^{\alpha} f(k \Delta) & \triangleq \int_{c}^{t} \frac{(t-\tau)^{\alpha-1}}{\gamma^{\gamma}(\alpha)} f(\tau) d \tau
\end{aligned}
$$

with, $\Delta$ : Sampling Period.

B. Definition of Fractional Order derivative:

It is defined as follows, by consideration of the equality:

$$
\begin{array}{r}
D^{\alpha} f(t)=\frac{d^{\alpha}}{d t^{\alpha}} f(t)= \\
\lim _{\square=0} \frac{1}{\square} \sum_{j=0}^{k}(-1)^{k}\left(\begin{array}{l}
n \\
k
\end{array}\right) f(t-k \square)
\end{array}
$$

And assuming that: $D^{\alpha} \approx D_{\square}^{\alpha}$, we have:

$$
\begin{gathered}
D_{\square}^{\alpha} f(t)=h^{-\alpha} \sum_{j=0}^{k}(-1)^{j}\left(\begin{array}{l}
\alpha \\
j
\end{array}\right) f(t- \\
j \square)
\end{gathered}
$$

The z-Transform of fractional derivation can be obtained as follows:

C. approximation of fractional order Transfer function:

$$
(1-z)^{\alpha}=\sum_{k=0}^{\infty}(-1)^{k}\left(\begin{array}{l}
\alpha \\
k
\end{array}\right) z^{k}=\sum_{k=0}^{\infty} \omega_{k}^{(\alpha)} z^{k}
$$

For the purpose of our approach we need to use an integer order model approximation of the fractional order model reference in order to implement the adaptation algorithm, for this aim we have used the so-called singularity function method [1]. For the of fractional second order system of the form (3) with $\mathrm{m} \mathrm{a}$ positive real number such that $0<\mathrm{m}<0.5$. We can approximate

$$
H(s)=\frac{1}{\left(\frac{s^{2}}{\omega^{2}}+2 \xi \frac{s}{\omega}+1\right)^{m}}
$$

by the function:

$$
H(s)=\frac{\left(\frac{s}{\omega}+1\right)\left(\frac{s}{\omega+1}\right)^{\beta}}{\left(\frac{s^{2}}{\omega^{2}}+2 \alpha \frac{s}{\omega}+1\right)}
$$

With $\alpha=\xi^{m}$ And $\beta=1-2 m$, also represented,

$$
H(s)=\frac{\left(\frac{s}{\omega}+1\right)}{\left(\frac{s^{2}}{\omega^{2}}+2 \alpha \frac{s}{\omega}+1\right)} \frac{\prod_{i=1}^{N-1}\left(1+\frac{s}{z_{i}}\right)}{\prod_{i=1}^{N}\left(1+\frac{s}{p_{i}}\right)}
$$

The singularities are given by:

$$
\begin{aligned}
& p_{j}=(a b)^{j-1} a . z_{1} \quad j=1,2,3, \ldots N \\
& z_{i}=(a b)^{i-1} z_{1} \quad i=2,3, \ldots N-1 \\
& \text { with } z_{1}=w \sqrt{b}, a=10^{\frac{\varepsilon_{p}}{10(1-\beta)}}, b=10^{\frac{\varepsilon_{p}}{10 \beta}}, \quad \beta=\frac{\log (a)}{\log (a b)}
\end{aligned}
$$

and $\varepsilon_{p}$ : tolerated error in $\mathrm{dB}$

The order of approximation $\mathrm{N}$ is computed by fixing the frequency band of work, specified by $\omega_{\max }$, so that:

$p_{N-1}<\omega_{\max }<p_{N}$ Which leads to:

$$
N=\text { int eger part of }\left[\frac{\log \left(\frac{\omega_{\max }}{p_{1}}\right)}{\log (a b)}+1\right]+1
$$

$H(s)$ can be then be written under a parametric shape function of order $\mathrm{N}+2$ :

$$
H(s)=\frac{b_{m 0} s^{N}+b_{m 1} s^{N-1}+\cdots+b_{m N}}{\partial \theta+a_{m 1} s^{N+1}+\cdots+a_{m N+2}}
$$

\section{Computation of coefficients:}




\section{FRACTIONAL ORDER MRAC}

The model reference adaptive system is one of the main approaches to adaptive control, in which the desired performance is expressed in terms of a reference model (a model that describes the desired input-output properties of the closed-loop system) and the parameters of the controller are adjusted based on the error between the reference model output and the system output. This can be represented by fig. 1

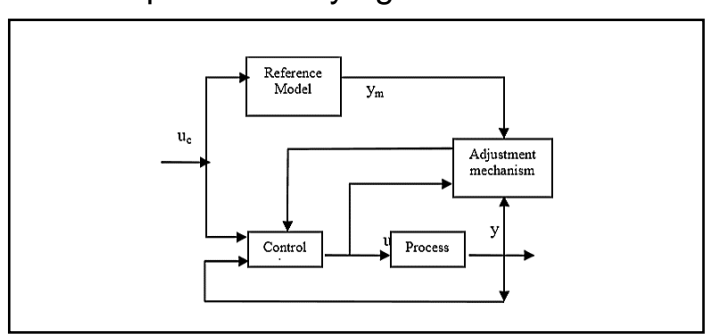

Fig. 1 Direct Model Reference Adaptive Control.

A. M.I.T. Rule:

We consider a closed loop system where the controller has an adjustable parameter vector $\square$. A model which output is ym specifies the desired closed loop response. Let e be the error between the closed loop system output $y$ and the model one ym, one possibility is to adjust the parameters such that the cost function:

$$
J(\theta)=\frac{1}{2} e^{2}
$$

be minimised. In order to make $\mathrm{J}$ small it is reasonable to change parameters in the direction of negative gradient $\mathrm{J}$, so:

$$
\frac{d \theta}{d t}=-\gamma \frac{\partial J}{\partial \theta}=-\gamma e \frac{\partial e}{\partial \theta}
$$

We get:

$$
\theta=-\frac{\gamma}{s^{m}} y_{m}\left(y-y_{m}\right)=-\frac{\gamma}{s^{m}} y_{m} e
$$

So:

$$
Y(t) \frac{d^{m} \theta}{d t^{m}}=-\gamma \cdot y_{m} \cdot e
$$

And

$$
\theta=-\gamma I^{m}\left[y_{m} \cdot e\right]
$$

the control law is calculated using this relation:

$$
u=\varphi^{T} \theta
$$

Where $\varphi$ is the regression vector containing the measured input and output signals $u$ and $y$ and the input reference signal uc.

\section{ACTIVE SUSPENSION MODEL}

The two degrees of freedom quarter model shown in Fig. 2 is the most commonly used model in the design studies for active suspension system. The simplest representation of a quarter vehicle model consists of a spring, damper and hydraulic or pneumatic actuators, which provide the desired force (controller actuator, F) in the suspension system, connecting the body to a single wheel, which is in turn connected to the ground via the tire spring

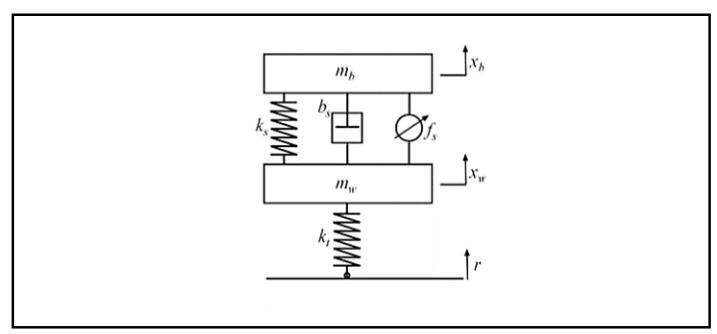

Fig. 2 Active suspension system..

The equations of motion of active suspension system are:

$$
\begin{gathered}
\ddot{x}_{1} M_{b}+c\left(\dot{x_{1}}-\dot{x}_{2}\right)+k_{1}\left(x_{1}-x_{2}\right)-F=0 \\
\ddot{x}_{2} M_{w}-c\left(\dot{x}_{1}-\dot{x}_{2}\right)+k_{1}\left(x_{2}-x_{1}\right)+ \\
k_{2}\left(x_{2}-w\right)+F=0
\end{gathered}
$$

\begin{tabular}{|c|c|c|c|}
\hline symbol & description & value & unit \\
\hline$F$ & Actuator force & - & $\mathrm{N}$ \\
\hline$c_{1}$ & $\begin{array}{l}\text { Suspension } \\
\text { damper } \\
\text { coefficient }\end{array}$ & 1000 & $\mathrm{Ns} / \mathrm{m}$ \\
\hline$k_{1}$ & Spring stiffness & 18600 & $\mathrm{~N} / \mathrm{m}$ \\
\hline$k_{2}$ & $\begin{array}{ll}\begin{array}{l}\text { Tire } \\
\text { stiffness }\end{array} & \text { spring } \\
\end{array}$ & 196000 & $\mathrm{~N} / \mathrm{m}$ \\
\hline$M_{b}$ & $\begin{array}{l}\text { Quarter car } \\
\text { sprung mass }\end{array}$ & 250 & $\mathrm{Kg}$ \\
\hline$M_{w}$ & Unsprung mass & 50 & $\mathrm{Kg}$ \\
\hline V & Vehicle velocity & $10-40$ & $\mathrm{~m} / \mathrm{s}$ \\
\hline$x_{1}$ & $\begin{array}{l}\text { Sprung mass } \\
\text { vertical } \\
\text { displacement }\end{array}$ & - & $\mathrm{m}$ \\
\hline$x_{2}$ & $\begin{array}{l}\text { Unsprung mass } \\
\text { vertical } \\
\text { displacement }\end{array}$ & - & $\mathrm{m}$ \\
\hline W & Road profile & - & $\mathrm{m}$ \\
\hline
\end{tabular}

The system physical parameters are given in Table I.

Table 1 SUSPENSION SYSTEM PARAMETERS 


\section{SIMULATION RESULTS AND DISCUSSION}

The proposed controller for active suspension system is verified with computer simulation using MATLAB SIMULINK program, with both conventional and fractional MRAC. The present controller is tested against different types of road profile (bumps) which are shown in fig. 3 to 9 Fig. shows the time response of the suspension system with fractional order integrator and the conventional integrator. It can be seen that they have the same response with a little bit of advantage in the fractional case and we can see it in the error shown in fig. 4, 6, 8, 10.

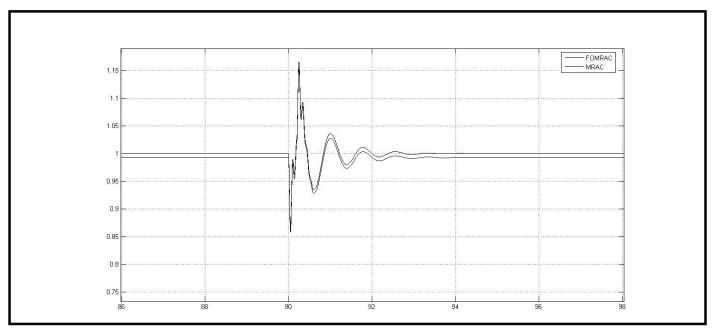

Fig. 3 Comparative response of MRAC and FOMRAC for $\alpha=1.2$

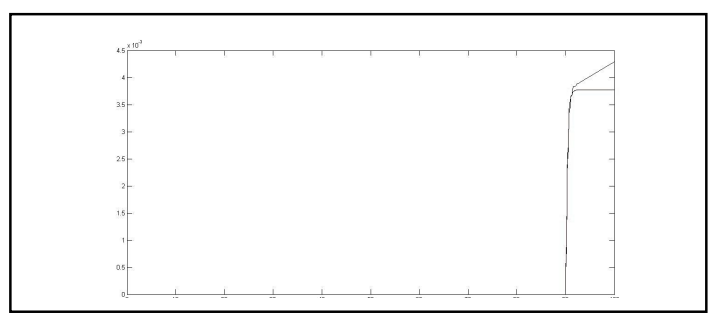

Fig. 4. Error signal MRAC and FOMRAC for $\alpha=$ 1.2

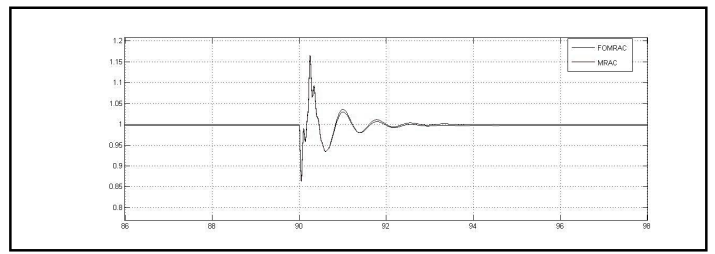

Fig. 5 Comparative response of MRAC and FOMRAC for $\alpha=1.4$

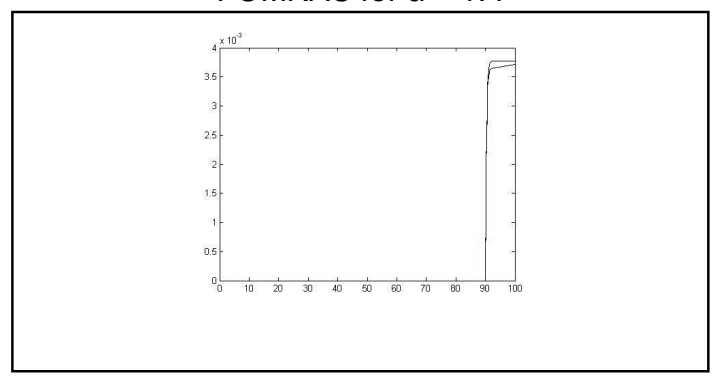

Fig. 6. Error signal MRAC and FOMRAC for $\alpha=1.4$

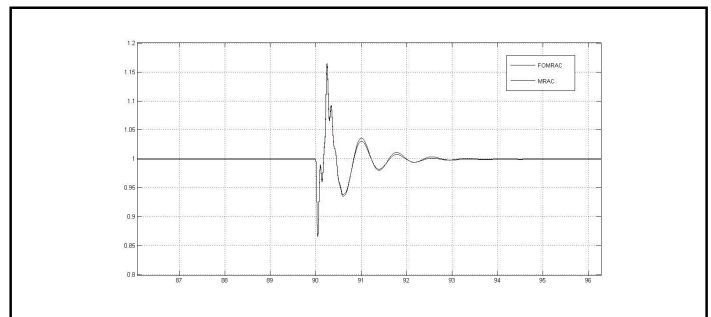

Fig. 7 Comparative response of MRAC and FOMRAC for $\alpha=1.6$

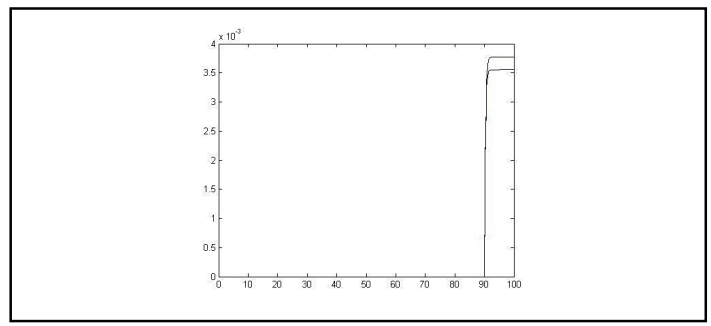

Fig. 8. Error signal MRAC and FOMRAC for $\alpha=$ 1.6

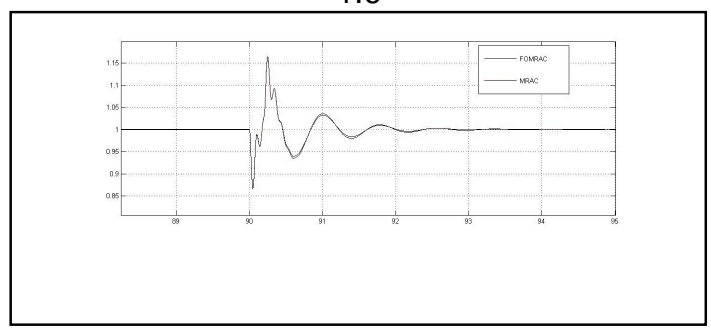

Fig. 9 Comparative response of MRAC and FOMRAC for $\alpha=1.8$

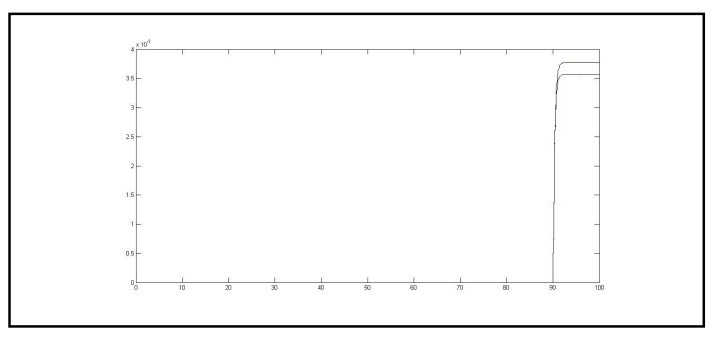

Fig. 10. Error signal MRAC and FOMRAC for $\alpha=$ 1.8

The main advantage with the use of fractional order integrator besides minimizing the tracking error is that we were able to choose a smaller value for the adaptation gain then in the case of conventional MRAC (smaller by seven times). We tested different values of $\alpha$ from 1.2 to 1.8 for the same value of the adaptation gain and we got the following results:

- for $\alpha=1.2$ here we notice that the best response is within the integrator 
which we can see in the tracking error figure.

- for $\alpha=1.4$ we can see that the response is already better but the response is nearly the same.

- for $\alpha=1.6$ we have better response with less error.

\section{CONCLUSION}

A fractional Model adaptive control algorithm which includes the use was presented and applied to the active suspension system control. We demonstrated that it can guarantee the closed loop stability with a good level of performances and high ability to reject perturbation. The simulations showed the improvement of performances of the adaptive control algorithm even when there are perturbations. Further research aims to improve the behavior and robustness of the active suspension system with application on a workbench.

\section{References}

[1] A. Charef, Analysis and Synthesis of fractal systems, Ph.D. Thesis, Drexel University, 1991.

[2] A.A. Jafari, S.M.A. Mohammadi, and M. H. Naseriyeh, Adaptive type-2 fuzzy backstepping control of uncertain fractionalorder nonlinear systems with unknown deadzone. Applied Mathematical Modelling, vol. 69, pp. 506-532, May 2019.

[3] W. Liu, G.-B. Bian, M. R. Ur Rahman, H. Zhang, $H$. Chen, and $W$. Wu, Fractional-order PID servo control based on decoupled visual model, Int J Adapt Control Signal Process. vol. 33, no. 8, pp 1265-1280, August 2019.

[4] B. M. Vinagre, I. Petras, I. Podlubny, and Y.Q. Chen, Y.Q. Using Fractional Order Adjustment Rules and Fractional Order Reference Models in Model-Reference Adaptive Control. In Nonlinear Dynamics, vol. 29, pp. 269-279, 2002.

[5] S. Ladaci, and A. Charef, Commande Adaptative à modèle de référence d'ordre Fractionnaire d'un bras artificiel. Revue Sciences et Communication, ENSET Oran Algeria, vol. 1, pp. 53-55, 2002

[6] S. Ladaci, and A. Charef, On Fractional Adaptive Control Nonlinear Dynamics, vol. 43, no. 4, pp. 365-378, March 2006.

[7] Y. Bensafia, S. Ladaci, Adaptive Control with Fractional Order Reference Model (Selected Paper) International Journal on Sciences and Techniques of Automatic control \& computer engineering - IJ-STA, vol. 5, no. 2, pp. 16141623, December 2011.
[8] S. Ladaci, A. Charef, Fractional Adaptive Control: A Survey In: Classification and Application of Fractals: New Research Edited by:Eric W. Mitchell and Scott R. Murray. 261-275, NOVA Publishers, USA, 2012

[9] Y. Bensafia, S. Ladaci, K. Khettab, A. Chemori, Fractional Order Model Reference Adaptive Control for SCARA Robot Trajectory Tracking. International Journal of Industrial and Systems Engineering, vol. 30, no. 2, pp. 138 - 156, September 2018.

[10] J. Ma, Y. Yao, and D. Liu, Fractional order model reference adaptive control for a hydraulic driven flight motion simulator. In Proc. 41st Southeastern Symposium on System Theory, SSST 2009, Tullahoma, TN, USA, pp. 340-343, 15-17 March, 2009.

[11] Y-L. He, and R-K. Gong, Application of Fractional-order Model Reference Adaptive Control on Industry Boiler Burning System. In Proc. of the Int. Conf. on Intelligent Computation Technology and Automation, ICICTA 2010, Changsha, Hunan, China, 1, pp. 750-753, May 11-12, 2010.

[12] J.I. Suarez, and B.M. Vinagre, A fractional model reference adaptive system: $A$ method of adjusting the parameters controller. Journal Européen des Systèmes Automatisés, vol. 42 , no. 6-8, pp. 977-998, 2008

[13] H. Balaska, S. Ladaci, and Y. Zennir, Conical Tank Level Supervision Using a Fractional Order Model Reference Adaptive Control Strategy. In: 15th International Conference on Informatics in Control, Automation and Robotics (ICINCO), INSTICC, 29-31 July 2018, Porto, Portugal, (2018).

[14] S. Coman, C. Boldisor, L. Floroian, Fractional adaptive control for a fractional-order insulineglucose dynamic model. 2017 International Conference on Optimization of Electrical and Electronic Equipment (OPTIM), Brasov, Romania, 25-27 May 2017.

[15] S. Djebbri, S. Ladaci, A. Metatla, and $H$. Balaska, Fractional-order model reference adaptive control of a multi-source renewable energy system with coupled DC/DC converters power compensation. Energy Systems, 2019.

[16] H. Balaska, S. Ladaci, H. Schulte, and A. Djouambi, Adaptive Cruise Control System for an Electric Vehicle Using a Fractional Order Model Reference Adaptive Strategy In: 9th IFAC/IFIP/IFORS/IISE/INFORMS Conference on Manufacturing Modelling, Management and Control, MIM 2019. IFAC. Berlin, Germany during August 28-30, 2019.

[17] M. Leegwater, An active suspension system capable of economically leveling a car during cornering. S010527 (TU/e), 2007.

[18] A. Rezanoori, M. K. A. Ariffin, A. Delgoshaei, Nawal. A. b. Abdul, Jalil, and Z. A. b. Zulkefli, A new method to improve passenger vehicle safety using intelligent functions in active suspension system. Engineering Solid Mechanics, vol. 7, pp. 313-330, 2019.

[19] K.D. Rao, Modeling, Simulation and Control of Semi Active Suspension System for Automobiles under MATLAB Simulink using PID Controller. Third International Conference on Advances in Control and Optimization of 
Dynamical Systems, Kanpur, India, March 1315, 2014.

[20] M. H. Ab. Talib, and I. Z. M. Darus, SelfTuning PID Controller for Active Suspension System with Hydraulic Actuator, 2013 IEEE Symposium on Computers \& Informatics, 2013.

[21] O. Ghasemalizadeh, S. Taheri, A. Singh, and J. Goryca, Semi-active suspension control using modern methodology: a comprehensive comparison study, 2014 NDIA Ground Vehicle Systems Engineering And Technology Symposium Modeling \& Simulation, Testing And Validation (Mstv) Technical Session,- NOVI, Michigan, August 12-14, 2014. 